\title{
Parâmetros biológicos do estágio ninfal de Amblyomma cajennense (Fabricius, 1787) (Acari: Ixodidae) em coelhos
}

\section{Biological parameters of the nymphal stage of Amblyomma cajennense (Fabricius, 1787) (Acari: Ixodidae) in rabbits}

\author{
Márcia Cristina de Azevedo Prata, Luciano da Silva Alonso, Argemiro Sanavria
}

\section{Resumo}

Com o objetivo de se obterem maiores informações sobre parâmetros relativos à fase ninfal do Amblyomma cajennense, foram realizadas 28 infestações com ninfas de 1 a 12 dias de idade em 20 coelhos de ambos os sexos e com pelagem uniforme nas cores branca ou preta. A fase não parasitária foi acompanhada sob condições controladas de laboratório (temperatura de $27^{\circ} \mathrm{C}$, umidade relativa do ar superior a $70 \%$ e $12 \mathrm{~h}$ de fotofase). Foram utilizadas 21.182 neoninfas, recolhendo-se 11.319 metaninfas, resultando em uma eficiência de infestação de $53,44 \%$. O período de ingurgitamento ninfal oscilou entre 3 e 5 dias com uma maior quantidade de ninfas levando 5 dias para completar o ingurgitamento. O tempo transcorrido entre o desprendimento da metaninfa e o término da ecdise ninfa/adulto oscilou entre 13 e 14 dias, com média de $13,43 \pm 0,50$ dias. Esse período não sofreu influência do sexo nem da cor da pelagem do coelho utilizado para ingurgitamento ninfal. Do total de metaninfas recolhidas, $95 \%$ realizaram ecdise completa, obtendo-se cerca de 10.700 adultos jovens, machos e fêmeas na proporção de 1:1.

Palavras chave: biologia; ninfas; Amblyomma cajennense; Ixodiadae

\section{Introdução}

Espécie de ampla dispersão no continente americano, o Amblyomma cajennense é uma praga que afeta animais domésticos, silvestres e o homem. Por necessitar três hospedeiros para completar seu ciclo, tem maior possibilidade de se infectar e transmitir patógenos como Bobesia e Ehrlichia.

Apesar das perdas determinadas pelo parasitismo, caracterizadas por queda na produtividade e na saúde dos animais e gastos com o uso incorreto de carrapaticidas, poucos estudos foram realizados objetivando um melhor conhecimento de seus aspectos bioecológicos. Drummond e Whetstone (1975) determinam alguns aspectos da oviposição de $A$. cajennense sob condições de laboratório, a partir de fêmeas ingurgitadas coletadas de bovinos. Uilenberg (1983) relatou a transmissão de Cowdria ruminatum a caprinos, através de ninfas de A. cajennense. Serra Freire (1983) registrou o poder indutor de paralisia em ruminantes por larvas, ninfas e adultos dessa espécie de carrapato. Olivieri e Serra Freire (1984) investigaram o estágio ninfal de $A$. cajennense a partir de infestações experimentais em coelhos. Cunha (1978) avaliou o poder toxicóforo dos três estágios evolutivos deste ixodídeo sobre coelhos.

O presente trabalho teve por objetivo fornecer maiores informações sobre as fases parasitária e não parasitária do estágio ninfal do $A$. cajennense, contribuindo para minimizar os prejuízos determinados pelo parasitismo através do estabelecimento de estratégias de controle mais racionais e eficazes.

\section{Material e Métodos}

O experimento foi conduzido no Laboratório de Doenças Parasitárias do Departamento de Epidemiologia e Saúde Pública no Instituto de Veterinária da Universidade Federal do Rio de Janeiro, situado no município de Seropédica, RJ, no período de março a setembro de 1994.

Para acompanhamento da fase parasitária, foram realizadas 28 infestações em 20 coelhos de ambos os sexos, com pelagem uniforme, nas cores branca ou preta. Cada infestação era composta por 400 a 1.500 ninfas de 1 a 12 dias de idade, provenientes de infestações experimentais com larvas em coelhos. No total do experimento, foram utilizadas 21.182 ninfas depositadas no pavilhão auricular dos coelhos, onde havia sido previamente adaptado um capuz de pano aderido à pele, pela extremidade inferior, com pasta UNA (água destilada, gelatina em foIha, glicerina e óxido de zinco). A extremidade superior do capuz era vedada com velcro, constituindo uma técnica modificada de Neitz et al. (1971). Os capuzes eram abertos diariamente para acompanhamento dos processos de fixação, ingurgitamento e desprendimento ninfal, até a queda de todas as metaninfas. Cinco dias após cada infestação, era efetuado o recolhimento das mesmas, que 
eram contadas, acondicionadas em seringas previamente preparadas e mantidas em estufa biológica para BOD a $27^{\circ} \mathrm{C}$ umidade relativa do ar superior a $70 \%$ e $12 \mathrm{~h}$ de fotofáse, para efetuarem a ecdise. Foi realizada a análise de variância (ANOVA) em nível de significância de 5\%, para verificar a existência de diferenças significativas quanto ao período de ecdise ninfa/adulto em relação ao sexo e/ou à cor da pelagem do coelho utilizado para ingurgitamento ninfal.

\section{Resultados e Discussão}

De 21.182 neoninfas utilizadas em 28 infestações, recolheram-se 11.319 metaninfas, resultando em uma eficiência de infestação de $53,44 \%$. O período de ingurgitamento ninfal oscilou entre 3 e 5 dias, com uma maior quantidade de ninfas levando 5 dias para ingurgitarem. Flechtmann (1977) verificou que as ninfas levam em média de 5 a 7 dias para completarem o ingurgitamento. Olivieri e Serra Freire (1984), em experimento com metodologia semelhante à do presente trabalho, registraram um período de ingurgitamento ninfal entre 4 e 8 dias, com média de 5,31 $\pm 0,18$ dias.

O período compreendido entre o desprendimento da metaninfa e o término da ecdise ninfa/adulto oscilou entre 13 e 14 dias, com média de 13,43 $\pm 0,50$ dias. Das 11.319 metaninfas obtidas, $95 \%$ completaram a ecdise, obtendo-se aproximadamente 10.700 adultos jovens e vivos, machos e fêmeas, na proporção de 1:1. Smith (1975) verificou que, em condições de laboratório, a ecdise ninfa/adulto leva de 14 a 18 dias para se completar. Flechtmann (1977) relatou para esse parâmetro um intervalo entre 23 e 25 dias, mas não informou sob que condições esses valores foram obtidos. Olivieri e Serra Freire (1984) observaram que a ecdise ninfa/adulto leva em média 19,57 $\pm 2,16$ dias para se completar, sendo obtidos $8,18 \pm 0,06$ adultos vivos, para cada 10 metaninfas recolhidas.
Os valores referentes à ecdise relacionada ao sexo e à cor da pelagem do hospedeiro utilizado para ingurgitamento em infestações experimentais com ninfas podem ser vistos na Tabela. Através da análise de variância em nível de significância de $5 \%$ pode-se verificar que não houve diferenças significativas quanto ao período de ecdise ninfa/ adulto relacionado ao sexo nem à cor da pelagem do hospedeiro, ou seja, o período de ecdise ninfa/adulto não foi afetado nem pelo sexo nem pela cor da pelagem do hospedeiro utilizado para ingurgitamento, quando foram realizadas infestações experimentais em coelhos. A metodologia utilizada não permitiu a realização da correlação entre o tempo de ingurgitamento ninfal e o sexo ou a cor da pelagem do coelho utilizado para ingurgitamento.

\section{Abstract \\ Biological parameters of the nymphal stage of Amblyomma cajennense (Fabricius, 1787) (Acari: (xodidae) in rabbits}

In an attempt to obtain more information on the parameters of the nymphal phase of Amblyomma cajennense, 28 infestations were conducted with 1 to 12 day nymphs in 20 rabbits of both sexes and uniform white or black color. Non-parasitic phase was followed under controlled laboratory conditions $\left(27^{\circ} \mathrm{C}\right.$ temperature, $70 \%$ relative air humidity, and $12 \mathrm{hr}$ photophase exposition). 21,182 neonymphs were used, out of which 11,319 metanymphs were collected, which accounted for and infestation efficiency of $53.44 \%$. The period of nymphal ingurgitation ranged from 3 to 5 days, with a higher number of nymphs taking 5 days to complete ingurgitation. The time lapsed between metanymph loosening and completion of the ecdisis nymph/adult ranged from 13 to 14 days, with an average of $13.43 \pm 0.50$ days. This period was not influenced neither by sex nor by hair color of rabbit used for nymphal ingurgitation. Out of the total of collected metanymphs, 95\%

Tabela - Valores da ecdise relacionada ao sexo e à cor da pelagem de coelhos utilizados para ingurgitamento, em infestações experimentais com ninfas de Amblyomma cajennense

\begin{tabular}{lcccr}
\hline $\begin{array}{l}\text { Coelho (sexo e } \\
\text { cor da pelagem }\end{array}$ & $\begin{array}{c}\text { No de } \\
\text { infestações }\end{array}$ & $\begin{array}{c}\text { № de } \\
\text { coelhos }\end{array}$ & $\begin{array}{c}\text { Idade da ninfa } \\
\text { infestante } \\
\text { (dias) }\end{array}$ & $\begin{array}{c}\text { Período entre desprendimento da } \\
\text { metaninfa e término da ecdise } \\
\text { (dias) } \bar{x} \pm \text { DP Limites (inferior - superior) }\end{array}$ \\
\hline Macho branco & 4 & 2 & 3 a 5 & $\begin{array}{r}13,50 \pm 0,58 \\
(13-14)\end{array}$ \\
Macho preto & 9 & 7 & 2 a 9 & $\begin{array}{r}13,33 \pm \pm 0,50 \\
(13-14)\end{array}$ \\
Fêmea branca & 10 & 7 & 1 a 12 & $13,50 \pm 0,53$ \\
Fêmea preta & 5 & 4 & 2 a 6 & $\begin{array}{r}13,40 \pm 0,55 \\
(13-14)\end{array}$ \\
\end{tabular}

$\overline{\mathrm{x}}=$ média; $\mathrm{DP}=$ desvio padrão. 
had complete ecdisis, being obtained approximately 10,700 young adults, male and female, on a 1:1 rate.

Key words: biology; nymphs; Amblyomma cajennense; Ixodidae

\section{Referências bibliográficas}

CUNHA, D.W. da. Estudos da toxicidade de alguns carrapatos comumente encontrados no Brasil (Acarina: Ixodidae). Itaguaí, 1978. 89 p. Dissertação (Mestrado) - Universidade Federal Rural do Rio de Janeiro.

DRUMMOND, R.O., WHETSTONE, T.M. Oviposition of the cayenne tick, Amblyomma cajennense (F.) in the laboratory. Ann. Entom. Soc. Am., v. 68, n. 2, p. 214-216, 1975.

FLECHTMANN, C.H.W. Ácaros de Importância Médico Veterinária. 2. ed. Nobel: São Paulo, 1977, 192 p.
NEITZ, W.O., BOUGHTON, F., WALTERS, H.W. Laboratory investigation on the life-cicle of the karoo paralysis tick (Ixodes rubicundus Neumann, 1904). Onderstepoort J. Res., v. 38, n. 3, p. 215-224, 1971.

OLIVIERI, J.A., SERRA FREIRE, N.M. Estádio ninfal do ciclo biológico de Amblyomma cajennense. Arq. Univ. Fed. Rural do Rio de Janeiro, v. 7, n. 2, p. 149-156, 1984.

SERRA FREIRE, N.M. Tick paralysis in Brasil. Trop. Anim. Hith. Prod., v. 15, p. 124-126, 1983.

SMITH, H.W. Some aspects of the ecology and life cycle of Amblyomma cajennense (Fabricius, 1787) in Trinidad and their influence on tick control measures. Ann. Trop. Med. Parasitol., v. 69, p. 121-129, 1975.

UILENBERG, G. Acquisitions nouvelles dons la connaissance du rôle vecteur des tiques du genere Amblyomma (Ixodidae). Rev. Elev. Med. Vet. Pays Trop., v. 36, n. 1, p. 61-66, 1983. 